American Journal of Economics and Business Administration 3 (3): 576-585, 2011

ISSN 1945-5488

(C) 2011 Science Publications

\title{
Credit Market Development and Economic Growth an Empirical Analysis for United Kingdom
}

\author{
Athanasios Vazakidis and Antonios Adamopoulos \\ Department of Applied Informatics, University of Macedonia, \\ 156 Egnatias Street, Thessaloniki, Greece
}

\begin{abstract}
Problem statement: This study investigated the causal relationship between credit market development and economic growth for UK for the period 1975-2007 using a Vector Error Correction Model (VECM). Questions were raised whether economic growth spurs credit market development taking into account the negative effect of inflation rate on credit market development. This study aimed to investigate the short-run and the long-run relationship between bank lending, gross domestic product and inflation rate applying the Johansen cointegration analysis. Approach: To achieve this objective classical and panel unit root tests were carried out for all time series data in their levels and their first differences. Johansen cointegration analysis was applied to examine whether the variables are cointegrated of the same order taking into account the maximum eigenvalues and trace statistics tests. Finally, a vector error correction model was selected to investigate the long-run relationship between economic growth and credit market development. Results: A short-run increase of economic growth per $1 \%$ induces an increase of bank lending $0.006 \%$, while an increase of inflation rate per $1 \%$ induces a relative decrease of bank lending per $1.05 \%$ in UK. The estimated coefficient of error correction term is statistically significant and has a negative sign, which confirms that there is not any problem in the long-run equilibrium between the examined variables. Conclusion: The empirical results indicated that there is a unidirectional causal relationship between economic growth and credit market development with direction from economic growth to credit market development and a bilateral causality between inflation and credit market development for United Kingdom. Bank development is determined by the size of bank lending directed to private sector at times of low inflation rates leading to higher economic growth rates.
\end{abstract}

Key words: Credit market, economic growth, panel unit roots, vector error correction model, growth rates, long-run equilibrium, financial development, stationarity test, domestic bank

\section{INTRODUCTION}

In recent years the relationship between financial development and economic growth has become an issue of extensive analysis. The question is whether financial development precedes or simply follows economic growth. A general proposition states that the development of the financial sector is expected to have a positive impact on economic growth. The main objective of this study was to investigate the causal relationship between economic growth and credit market development taking into account the effect of inflation rate on credit market development. Economic growth favors credit market development at times of low inflation rates.

The literature on financial liberalization has emphasized abolishing interest rate ceilings and encourages free competition among banks as the way forward to achieve economic growth. However, it has largely overlooked the possibility that endogenous constraints in the credit market, such as imperfect information, could be a significant obstacle to efficient credit allocation even when assuming that banks are free from interest rate ceilings. Stiglitz and Weiss (1981) were the first to consider the importance of banks in allocating credit efficiently, particularly to new and innovative investments.

A high risk premium would only encourage the riskier borrowers, as the higher the risk the higher the expected return from investment. The expected return of the borrowers is an increasing function of the riskiness of their projects, the higher the risk the higher the return. This fact would discourage less risky investments from taking place, although they could be

Corresponding Author: Athanasios Vazakidis, Department of Applied Informatics, University of Macedonia, 156 Egnatias Street, Thessaloniki, Greece 
more productive (selection effect). Safe borrowers, which deal with banks only, will be left with no other choice. At times of high interest rates, investors would favour investments with a high probability of default (incentive effect). Reducing opportunities to innovate will have a negative impact on economic growth in the long run. King and Levine (1993) use different measures of bank development for several countries and find that banking sector development can spur economic growth in the long run.

The effect of inflation on financial development is much more complicated. A rise of initially low inflation may not lead to detrimental consequences for financial activity, whereas a rise in the rate of inflation that is initially high may substantially depress activity on financial markets and entail reduction in financial depth. If this hypothesis is true, then there is an inflation threshold in relationship between financial depth and inflation and this threshold can be regarded as an optimum rate of inflation with respect to financial development and therefore be a target for monetary authorities.

Ball and Mankiw (1995) indicate that higher inflation necessarily raises inflation uncertainty. Higher inflation uncertainty increases the riskiness of all credits and therefore even previously 'high quality borrowers' get treated as the risky ones. To assure that credits are paid back banks may resort to more severe credit rationing. Levine (2002) emphasizes the critical importance of the banking system in economic growth and highlight circumstances when banks can actively spur innovation and future growth by identifying and funding productive investments.

The model hypothesis predicts that economic growth facilitates credit market development taking into account the negative effect of inflation rate on credit market development and economic growth.

This study has two objectives:

- To examine the stationarity tests of the examined variables estimating classical and panel unit roots tests

- To examine the long run relationship among economic growth, inflation rate and credit market development using Johansen co-integration analysis taking into account classical and panel unit root tests

The remainder of the study proceeds as follows: Initially the data and the specification of the multivariate VAR model are described. For this purpose stationarity test and Johansen co-integration analysis are examined taking into account the estimation of vector error correction model.

Finally, the empirical results are presented analytically and some discussion issues resulted from this empirical study are developed shortly, while the final conclusions are summarized relatively.

\section{MATERIALS AND METHODS}

Data and specification model: In this study the method of Vector Autoregressive Model (VAR) is applied to estimate the effects of economic growth and inflation rate on credit market development. The use of this methodology predicts the cumulative effects taking into account the dynamic response among credit market development and the other examined variables (Shan, 2005).

In order to test the causal relationships, the following multivariate model is to be estimated Eq. 1:

$\mathrm{BC}=\mathrm{f}(\mathrm{CPI}, \mathrm{GDP})$

Where:

$\mathrm{BC}=$ The domestic bank credits to private sector

$\mathrm{CPI}=$ The consumer price index

GDP $=$ The gross domestic product

Following the empirical studies of King and Levine (1993); Vazakidis (2006); Vazakidis and Adamopoulos (2009b; 2009c; 2010); Athanasios and Antonios (2010), the variable of economic growth (GDP) is measured by the rate of change of real GDP, while the credit market development is expressed by the domestic Bank Credits to private sector (BC) as a percentage of GDP.

This measure has a basic advantage from any other monetary aggregate as a proxy for credit market development. Although it excludes bank credits to the public sector, it represents more accurately the role of financial intermediaries in channeling funds to private market participants (Renfro, 2006; Vazakidis and Adamopoulos, 2009a; 2009b; Adamopoulos, 2010b).

The data that are used in this analysis are annual covering the period 1975-2007 for United Kingdom, regarding 2000 as a base year and are obtained from international financial statistics yearbook IMF (2006). All time series data are expressed in their levels and Eviews econometric computer software is used for the estimation of the model.

Unit root tests: For univariate time series analysis involving stochastic trends, Phillips and Perron (1988) and Kwiatkowski et al. (1992) (KPSS) unit root tests are 
calculated for individual series to provide evidence as to whether the variables are integrated. This is followed by a multivariate co-integration analysis.

Phillips and Perron (1988) test is an extension of the Dickey and Fuller (1979), which makes the semiparametric correction for autocorrelation and is more robust in the case of weakly autocorrelation and heteroskedastic regression residuals. According to Choi (1992), the Phillips and Perron (1988) test appears to be more powerful than the ADF test for the aggregate data.

Although the Phillips and Perron (1988) test gives different lag profiles for the examined variables (time series) and sometimes in lower levels of significance, the main conclusion is qualitatively the same as reported by the Dickey and Fuller (1979) test. Since the null hypothesis in the Augmented (Dickey and Fuller 1979) test is that a time series contains a unit root, this hypothesis is accepted unless there is strong evidence against it. However, this approach may have low power against stationary near unit root processes.

Following the studies of Vazakidis and Adamopoulos (2009c; 2010), the Phillips-Perron unit root test according to

Laopodis and Sawhney (2007), is very general and can be used in the presence of heteroscedastic and autocorrelated innovations is specified as follows Eq. 2a:

$$
\ln (1+\mathrm{r})=\alpha+\beta\left(\frac{\mathrm{t}-\mathrm{T}}{2}\right)+\delta \ln \left(1+\mathrm{r}_{\mathrm{t}-1}\right)+\zeta_{\mathrm{t}}
$$

for $t=1,2, \ldots ., T$ where $r_{t}$ denotes interest rate at time $t$, $(\mathrm{t}-\mathrm{T} / 2)$ is a time trend and $\mathrm{T}$ is the sample size.

Equation 2 tests three hypotheses: The first hypothesis is that the series contains a unit root with a drift with a drift and a time trend: $\mathrm{H}_{0}^{1}: \delta=1$. The second hypothesis is that the series contains a unit root but without a time trend: $\mathrm{H}_{0}^{2}: \beta=0, \delta=1$. The third hypothesis is that the series contains a unit root but without a drift or a time trend: $\mathrm{H}_{0}^{3}: \mathrm{a}=0, \beta=0, \delta=1$. The statistics that are used to test each hypothesis are $\mathrm{Z}\left(\mathrm{t}_{\delta}\right), \mathrm{Z}\left(\Phi_{2}\right), \mathrm{Z}\left(\Phi_{3}\right)$, respectively and their corresponding equations are as follows Eq. $2 \mathrm{~b}-2 \mathrm{~g}$ :

$$
\begin{aligned}
& \mathrm{Z}\left(\mathrm{t}_{\delta}\right)=\left(\frac{\sigma_{0}}{\sigma_{\mathrm{T} 1}}\right) \mathrm{t}_{\sigma}-\left(\frac{\mathrm{T}^{3}}{3^{1 / 2} 4 \mathrm{D}_{\mathrm{xx} \mathrm{T} \mathrm{T}}^{1 / 2}}\right)\left(\sigma_{\mathrm{Tl}}^{2}-\sigma_{0}^{2}\right) \\
& \mathrm{Z}\left(\Phi_{3}\right)=\left(\frac{\sigma_{0}^{2}}{\sigma_{\mathrm{T} 1}^{2}}\right) \Phi_{3}-\left(\frac{1}{2 \sigma_{\mathrm{Tl}}^{2}}\right)\left(\sigma_{\mathrm{T} 1}^{2}-\sigma_{0}^{2}\right) \\
& \mathrm{x}\left[\mathrm{T}(\delta-1)-\left(\frac{\mathrm{T}^{6}}{48 \mathrm{D}_{\mathrm{xx}}}\right)\left(\sigma_{\mathrm{Tl}}^{2}-\sigma_{0}^{2}\right)\right]
\end{aligned}
$$

$$
\begin{aligned}
& \mathrm{Z}\left(\Phi_{2}\right)=\left(\frac{\sigma_{0}^{2}}{\sigma_{\mathrm{Tl}}^{2}}\right) \Phi_{2}-\left(\frac{1}{3 \sigma_{\mathrm{Tl}}^{2}}\right)\left(\sigma_{\mathrm{Tl}}^{2}-\sigma_{0}^{2}\right) \\
& \mathrm{x}\left[\mathrm{T}(\delta-1)-\left(\frac{\mathrm{T}^{6}}{48 \mathrm{D}_{\mathrm{xx}}}\right)\left(\sigma_{\mathrm{Tl}}^{2}-\sigma_{0}^{2}\right)\right]
\end{aligned}
$$

Where:

$$
\begin{aligned}
& \Phi_{3}=\frac{\mathrm{T}\left(\sigma_{0}^{2}-\left(\overline{\mathrm{r}}-\overline{\mathrm{r}}_{\mathrm{t}-1}\right)^{2}-\sigma^{2}\right)}{2 \sigma^{2}} \\
& \Phi_{2}=\frac{\mathrm{T}\left(\sigma_{0}^{2}-\sigma^{2}\right)}{3 \sigma^{2}}
\end{aligned}
$$

And:

$\sigma^{2}=$ OLS residual variance

$\sigma_{0}^{2}=$ Variance under the particular hypothesis for the standard t-test for $\delta=1$

$\mathrm{D}_{\mathrm{xx}}=$ Determinant of the $\left(\mathrm{X}^{\prime} \mathrm{X}\right)$

$\mathrm{X}=\mathrm{T}_{3}$ matrix of explanatory variables in Eq. $2 \mathrm{a}$

$\sigma_{\mathrm{Tl}}=$ Consistent estimator of the variance of $\zeta$ and is computed as follows:

$\sigma_{\mathrm{Tl}}^{2}=\sum_{\mathrm{t}=1}^{\mathrm{T}} \frac{\zeta_{\mathrm{t}}^{2}}{\mathrm{~T}}+\frac{\left(2 \sum_{\mathrm{t}=1}^{1} \sum_{\mathrm{t}=\mathrm{s}=1}^{\mathrm{T}}(1-\mathrm{s} /(1+1)) \zeta_{\mathrm{t}} \zeta_{\mathrm{t}-\mathrm{s}}\right)}{\mathrm{T}}$

where, $\mathrm{s}$ and 1 are the lag truncation numbers and $\mathrm{s}<1$. The estimator $\sigma_{\mathrm{Tl}}$ is consistent under general conditions because it allows for effects of serially correlated and heterogeneously distributed innovations. The three statistics are evaluated under various lags $(1=0-12)$.

Since the null hypothesis in the Augmented Dickey and Fuller (1979) test is that a time series contains a unit root, this hypothesis is accepted unless there is strong evidence against it. However, this approach may have low power against stationary near unit root processes. Kwiatkowski et al. (1992) present a test where the null hypothesis states that the series is stationary.

The KPSS test complements the Augmented (Dickey and Fuller, 1979) test in that concerns regarding the power of either test can be addressed by comparing the significance of statistics from both tests. A stationary series has significant Augmented (Dickey and Fuller 1979) statistics and insignificant KPSS. Following the studies of Chang (2002); Adamopoulos (2010a; 2010b; 2010c) and Athanasios and Antonios (2010), according to Kwiatkowski et al. (1992) the test of KPSS assumes that a time series can be composed into three components, a deterministic time trend, a random walk and a stationary error: 


$$
\mathrm{y}_{\mathrm{t}}=\delta \mathrm{t}+\mathrm{r}_{\mathrm{t}}+\varepsilon_{\mathrm{t}}
$$

Where:

$\mathrm{r}_{\mathrm{t}}=$ Random walk $\mathrm{r}_{\mathrm{t}}=\mathrm{r}_{\mathrm{t}-1}+\mathrm{u}_{\mathrm{t}}$.

$\mathrm{u}_{\mathrm{t}}=\operatorname{iid}\left(0, \sigma_{\mathrm{u}}^{2}\right)$

The stationarity hypothesis implies that $\sigma_{\mathrm{u}}^{2}=0$.

Under the null, $\mathrm{y}_{\mathrm{t}}$, is stationary around a constant $(\delta=0)$ or trend-stationary $(\delta \neq 0)$. In practice, one simply runs a regression of $y_{t}$ over a constant (in the case of level-stationarity) or a constant plus a time trend (in the case of trend-stationary). Using the residuals, $\mathrm{e}_{\mathrm{i}}$, from this regression, one computes the LM statistic:

$$
\mathrm{LM}=\mathrm{T}^{-2} \sum_{\mathrm{t}=1}^{\mathrm{T}} \mathrm{S}_{\mathrm{t}}^{2} / \mathrm{S}_{\mathrm{\varepsilon t}}^{2}
$$

where, $S_{\varepsilon t}^{2}$ is the estimate of variance of $\varepsilon_{t}$ :

$$
\mathrm{S}_{\mathrm{t}}=\sum_{\mathrm{i}=1}^{\mathrm{t}} \mathrm{e}_{\mathrm{i}}, \mathrm{t}=1,2, \ldots . \mathrm{T}
$$

The distribution of LM is non-standard: The test is an upper tail test and limiting values are provided by Kwiatkowski et al. (1992) via Monte Carlo simulation. To allow weaker assumptions about the behaviour of $\varepsilon_{\mathrm{t}}$, one can rely, following Phillips (1987) on the Newey and West (1987) estimate of the long-run variance of $\varepsilon_{\mathrm{t}}$ which is defined as:

$$
S^{2}(1)=T^{-1} \sum_{t=1}^{T} e_{i}^{2}+2 T^{-1} \sum_{s=1}^{1} w(s, 1) \sum_{t=s+1}^{T} e_{i} e_{i-k}
$$

where, $w(s, 1)=1-\mathrm{s} /(1+1)$. In this case the test becomes:

$$
v=T^{-2} \sum_{t=1}^{T} S_{t}^{2} / S^{2}(1)
$$

Which is the one considered here. Obviously the value of the test will depend upon the choice of the 'lag truncation parameter', 1. Here we use the sample autocorrelation function of $\Delta \mathrm{e}_{\mathrm{t}}$ to determine the maximum value of the lag length 1) statistics.

The KPSS statistic tests for a relative lag-truncation parameter (1), in accordance with the default Bartlett kernel estimation method (since it is unknown how many lagged residuals should be used to construct a consistent estimator of the residual variance), rejects the null hypothesis in the levels of the examined variables for the relative lag-truncation parameter (1).

Besides classical unit roots in this study the methodology of panel units roots tests is examined.

Following the study of Christopoulos and Tsionas (2004) and Levin et al. (2002) denoted as LLC panel unit root tests respectively resulted to the same conclusion. They consider the following basic ADF specification Eq. 3a-3e:

$\Delta y_{i t}=\alpha y_{i t-1}+\sum_{j=1}^{p_{i}} \beta_{i j} \Delta y_{i t-j}+X_{i t}^{\prime} \delta+\varepsilon_{i t}$

where we assume a common $\alpha=\rho$ - 1 but allow the lag order for the difference terms, $p_{i}$ to vary across cross-sections. The null and alternative hypotheses for the tests may be written as: $\mathrm{H}_{0}: \mathrm{a}=0$ but $\mathrm{H}_{1}: \mathrm{a}<0$. In LLC panel unit root test, the null hypothesis is the existence of a unit root, while under the alternative, there is no unit root.

Levin et al. (2002) consider the model:

$\mathrm{y}_{\mathrm{it}}=\rho_{\mathrm{i}} \mathrm{y}_{\mathrm{i}, \mathrm{t}-1}+\mathrm{z}_{\mathrm{it}}^{\prime} \gamma+\mathrm{u}_{\mathrm{it}}$

where, $z_{i t}$ are deterministic variables, $u_{i t}$ is $\operatorname{iid}\left(0, \sigma^{2}\right)$ and $\rho_{i}=\rho$. They assume that there is a common unit root process so that $\rho$ is identical across cross-sections.

The LLC test statistic is a t-statistic on $\rho$ given by:

$\mathrm{t}_{\rho}=\frac{(\hat{\rho}-1) \sqrt{\sum_{\mathrm{i}=1}^{\mathrm{N}} \sum_{\mathrm{t}=1}^{\mathrm{T}} \tilde{y}_{\mathrm{i}, t-1}^{2}}}{\mathrm{~s}_{\mathrm{e}}}$

Where:

$\tilde{y}_{i t}=y_{i t}-\sum_{s=1}^{T} h(t, s) y_{i s}, \tilde{u}_{i t}=u_{i t}-\sum_{s=1}^{T} h(t, s) u_{i s}, h(t, s)$

$=\mathrm{z}_{\mathrm{t}}^{\prime}\left(\sum_{\mathrm{t}=1}^{\mathrm{T}} \mathrm{z}_{\mathrm{t}} \mathrm{z}_{\mathrm{t}}^{\prime}\right) \mathrm{z}_{\mathrm{s}}, \mathrm{s}_{\mathrm{e}}^{2}=(\mathrm{NT})^{-1} \sum_{\mathrm{i}=1}^{\mathrm{N}} \sum_{\mathrm{t}=1}^{\mathrm{T}} \tilde{\mathrm{u}}_{\mathrm{it}}^{2}$

and $\hat{\rho}$ is the OLS estimate of $\rho$. It can be shown that if there are only fixed effects in the model, then and if there are fixed effects and a time trend:

$\sqrt{\mathrm{N} T}(\hat{\rho}-1)+3 \sqrt{\mathrm{N}} \rightarrow \mathrm{N}\left(0, \frac{51}{5}\right)$

$\sqrt{\mathrm{N}}(\mathrm{T}(\hat{\rho}-1)+7.5) \rightarrow \mathrm{N}\left(0, \frac{2895}{112}\right)$

Im et al. (1997) denoted as IPS panel unit root tests respectively resulted to the same conclusion. In IPS 
panel unit root test, the null hypothesis is the existence of a unit root. The IPS statistic is based on averaging individual Dickey and Fuller (1979) unit root test $\left(\mathrm{t}_{\mathrm{i}}\right)$ according to Eq. 4:

$$
\mathrm{t}_{\text {IPS }}=\frac{\sqrt{\mathrm{N}}\left(\overline{\mathrm{t}}-\mathrm{E}\left[\mathrm{t}_{\mathrm{i}} \mid \rho_{\mathrm{i}}=0\right]\right)}{\sqrt{\operatorname{var}\left[\mathrm{t}_{\mathrm{i}} \mid \rho_{\mathrm{i}}=0\right]}} \rightarrow \mathrm{N}(0,1)
$$

Where:

$$
\overline{\mathrm{t}}=\mathrm{N}^{-1} \sum_{\mathrm{i}=1}^{\mathrm{N}} \mathrm{t}_{\mathrm{i}}
$$

The moments of $E\left[t_{i} \mid \rho_{i}=0\right]$ and $\operatorname{var}\left[t_{i} \mid \rho_{i}=0\right]$ are obtained by Monte Carlo simulation and are tabulated in IPS (Christopoulos and Tsionas, 2004).

Following the studies of Christopoulos and Tsionas (2004); Kiran et al. (2009) and Breitung (2001) finds that IPS suffers a dramatic loss of power when individual trends are included and the test is sensitive to the specification of deterministic trends. The Breitung (2001) denoted as (BR) panel unit root test assumes that there is a common unit root process so that $\rho_{\mathrm{i}}$ is identical across cross-sections. Under the null hypothesis, there is a unit root, while under the alternative, there is no unit root. LLC and Breitung examine the same basic ADF specification: The Breitung panel unit root test differs from LLC in two distinct ways. First, only the autoregressive portion (and not the exogenous components) is removed when constructing the standardized proxies Eq. 5a-5e:

$$
\Delta \tilde{y}_{i t}=\left(\Delta y_{i t}-\sum_{j=1}^{p_{i}} \beta_{i j} \Delta y_{i t-j}\right) / s_{i}
$$

And:

$$
\tilde{y}_{i t-1}=\left(y_{i t-1}-\sum_{j=1}^{p_{i}} \beta_{i j} \Delta y_{i t-j}\right) / s_{i}
$$

where, $\tilde{\beta}, \beta$ and $s_{i}$ are as defined for LLC.

Second, the proxies are transformed and detrended:

$$
\Delta \mathrm{y}_{\mathrm{it}} *=\sqrt{\frac{(\mathrm{T}-\mathrm{t})}{(\mathrm{T}-\mathrm{t}+1)}}\left(\Delta \tilde{\mathrm{y}}_{\mathrm{it}}-\frac{\Delta \tilde{\mathrm{y}}_{\mathrm{it}+1}+\ldots . .+\Delta \mathrm{y}_{\mathrm{iT}}}{\mathrm{T}-\mathrm{t}}\right)
$$

And:

$$
\mathrm{y}_{\mathrm{it}} *=\tilde{\mathrm{y}}_{\mathrm{it}}-\tilde{\mathrm{y}}_{\mathrm{i} 1}-\frac{\mathrm{t}-1}{\mathrm{~T}-1}\left(\tilde{\mathrm{y}}_{\mathrm{iT}}-\tilde{\mathrm{y}}_{\mathrm{i} 1}\right)
$$

The persistence parameter is estimated from the pooled proxy equation:
$\Delta \mathrm{y}_{\mathrm{it}} *=\mathrm{a}_{\mathrm{it}-1} *+v_{\mathrm{it}}$

Breitung test shows that under the null, the resulting estimator $\mathrm{a}^{*}$ is asymptotically distributed as a standard normal. The Breitung panel unit root test requires only a specification of the number of lags used in each cross section $\mathrm{ADF}$ regression, $\mathrm{p}_{\mathrm{i}}$ and the exogenous regressors. In contrast with LLC, no kernel computations are required.

The econometric software Eviews which is used to conduct the PP and KPSS tests, reports the simulated critical values based on response surfaces. The results of the Phillips and Perron (1988) and Kwiatkowski et al. (1992) unit root test and of Levin et al. (2002); Im et al. (1997) Katos et al., 1996 and Breitung (2001) panel unit roots tests for each variable appear in Table 1a-b. If the time series (variables) are non-stationary in their levels, they can be integrated with integration of order 1 , when their first differences are stationary.

Johansen co-integration analysis: Following the studies of Vazakidis and Adamopoulos (2009c); Athanasios and Antonios (2010), since it has been determined that the variables under examination are integrated of order 1 , then the co-integrated test is performed. The testing hypothesis is the null of non-cointegration against the alternative that is the existence of co-integration using the Johansen maximum likelihood procedure (Johansen, 1988).

Once a unit root has been confirmed for a data series, the question is whether there exists a long-run equilibrium relationship among variables. According to Granger (1986), a set of variables, $\mathrm{Y}_{\mathrm{t}}$ is said to be cointegrated of order $(d, b)$-denoted $C I(d, b)$-if $Y_{t}$ is integrated of order $d$ and there exists a vector, $\beta$, such that $\beta^{\prime} Y_{t}$ is integrated of order $(d-b)$.

Co-integration tests in this study are conducted using the method developed by Johansen and Juselius (1990). The multivariate co-integration techniques developed by Johansen and Juselius (1990; 1992) using a maximum likelihood estimation procedure allows researchers to estimate simultaneously models involving two or more variables to circumvent the problems associated with the traditional regression methods used in previous studies on this issue. Therefore, the Johansen method applies the maximum likelihood procedure to determine the presence of co-integrated vectors in non-stationary time series.

Following the study of Chang and Caudill (2005); Johansen (1988) and Osterwald-Lenum (1992) propose two test statistics for testing the number of co-integrated vectors (or the rank of $\Pi$ ): The trace $\left(\lambda_{\text {trace }}\right)$ and the maximum eigenvalue $\left(\lambda_{\max }\right)$ statistics. 
Am. J. of Economics and Business Administration 3 (3): 576-585, 2011

Table 1a: PP, KPSS unit root tests

\begin{tabular}{|c|c|c|c|c|c|}
\hline \multirow[b]{2}{*}{ Variables } & \multicolumn{3}{|l|}{ PP_test stat } & \multicolumn{2}{|l|}{ KPSS test stat } \\
\hline & $\mathrm{Z}\left(\Phi_{3}\right)$ & $\mathrm{Z}\left(\Phi_{2}\right)$ & $\mathrm{Z}\left(\mathrm{t}_{\delta}\right)$ & $\mathrm{h}_{\mathrm{c}}$ & $\mathrm{h}_{\mathrm{t}}$ \\
\hline \multicolumn{6}{|l|}{ In levels } \\
\hline $\mathrm{BC}$ & $2.35(\mathrm{k}=3)$ & $0.74(\mathrm{k}=3)$ & $-2.46(\mathrm{k}=1)$ & $3.06(1=0)$ & $0.19 *(1=0)$ \\
\hline CPI & $4.44(\mathrm{k}=4)$ & $-1.43(\mathrm{k}=0)$ & $-1.87(\mathrm{k}=1)$ & $3.27(1=0)$ & $0.58(1=0)$ \\
\hline GDP & $5.07(\mathrm{k}=2)$ & $1.65(\mathrm{k}=1)$ & $-1.13(\mathrm{k}=2)$ & $0.74(1=0)$ & $0.17 *(1=0)$ \\
\hline \multicolumn{6}{|c|}{ In 1st differences } \\
\hline$\Delta \mathrm{BC}$ & $-2.71(\mathrm{k}=3)$ & $-3.21 *(\mathrm{k}=2)$ & $-3.71 *(\mathrm{k}=2)$ & $0.25(1=0)$ & $0.04(1=0)$ \\
\hline$\Delta \mathrm{CPI}$ & $\begin{array}{l}-0.11(\mathrm{k}=0) \\
*, * *, * * *\end{array}$ & $-2.96(\mathrm{k}=4)$ & $-3.22 *, * *(\mathrm{k}=2)$ & $0.30(1=0)$ & $0.06(1=0)$ \\
\hline$\Delta \mathrm{GDP}$ & $-2.79(\mathrm{k}=4)$ & $-4.51(\mathrm{k}=2)$ & $-4.98(\mathrm{k}=1)$ & $0.32 * * *(1=1)$ & $0.03(1=1)$ \\
\hline
\end{tabular}

$\mathrm{Z}(\Phi 3), \mathrm{Z}(\Phi 2), \mathrm{Z}(\mathrm{t} \delta)$, are the PP statistics, hc and ht are the KPSS statistics, $\mathrm{k}, \mathrm{l}=$ bandwidth lengths: Newey-West using Bartlett kernel, the critical values at 1,5 and $10 \%$ are $-2.62,-1.95,-1.61$, for $Z(\Phi 3),-3.65,-2.96,-2.62$ for $Z(\Phi 2)$, and for $-4.29,-3.56,-3.21$ for $Z(t \delta)$, respectively, The critical values at 1,5 and $10 \%$ are $0.73,0.46$ and 0.34 for hc and $0.21,0.14$ and 0.11 for ht respectively (Kwiatkowski et al., 1992, Table $1),{ }^{*}, * *, * * *$ indicate that those values are not consistent with relative hypotheses at the 1,5 and $10 \%$ levels of significance relatively

Table 1b: IPS, LLC, BR panel unit root tests

\begin{tabular}{|c|c|c|c|c|}
\hline \multirow[b]{2}{*}{ Variables } & \multicolumn{2}{|c|}{ LLC test stat } & \multirow{2}{*}{$\begin{array}{c}\text { IPS test sta } \\
\text { IPS }_{\mathrm{C}}\end{array}$} & \multirow{2}{*}{$\begin{array}{c}\text { BR test stat } \\
\mathrm{BR}_{\mathrm{T}}\end{array}$} \\
\hline & $\mathrm{LLC}_{\mathrm{C}}$ & $\mathrm{LLC}_{\mathrm{T}}$ & & \\
\hline \multicolumn{5}{|l|}{ In levels } \\
\hline $\mathrm{BC}$ & 0.02 & -0.26 & 0.70 & 0.05 \\
\hline GDP & 0.03 & -0.10 & 1.75 & 0.03 \\
\hline CPI & -0.005 & -0.15 & -0.82 & 0.01 \\
\hline \multicolumn{5}{|l|}{ In 1st differences } \\
\hline$\Delta \mathrm{BC}$ & -0.55 & -0.64 & -3.21 & 0.06 \\
\hline$\Delta \mathrm{GDP}$ & -0.80 & -0.91 & -4.01 & 0.04 \\
\hline$\Delta \mathrm{CPI}$ & -0.49 & -0.52 & -3.08 & 0.02 \\
\hline
\end{tabular}

Notes: LLC is the Levin, Lin and Chu t-test and IPS is the Im, Pesaran and Shin t-test test for unit root test in the model. The critical values for LLC $\mathrm{C}_{\mathrm{C}}$ test are 0.35 and -3.29 including only constant in levels and first differences respectively. The critical values for $\mathrm{LLC}_{\mathrm{T}}$ test are 0.02 and -2.78 including constant and trend in levels and first differences respectively. The critical values for IPS $\mathrm{s}_{\mathrm{c}}$ test are 3.97 and -4.06 including only constant in levels and first differences respectively. The critical values for $\mathrm{BR}_{\mathrm{T}}$ test are 0.79 and -3.06 including constant and trend in levels and first differences respectively

Table 2: Johansen Co-integration tests(BC, GDP, CPI) Johansen test statistics

\begin{tabular}{|c|c|c|c|c|}
\hline Testing & Critic: & & Critic: & \\
\hline Hypothesis & $\lambda_{\mathrm{rr}}$ & $5 \%$ & $\lambda_{\mathrm{m}}$ & $5 \%$ \\
\hline None* & 50.96 & 17.68 & 57.88 & 24.0 \\
\hline At most 1 & 6.90 & 11.03 & 6.92 & 12.36 \\
\hline At most 2 & 0.02 & 4.16 & 0.02 & 4.16 \\
\hline
\end{tabular}

Trace test and maximum eigenvalue tests indicate 1 co-integrating eqn(s) at the 0.05 level; *: Denotes rejection of he hypothesis at the 0.05 level; **: MacKinnon et al. (1999) p-values

The Likelihood Ratio statistic (LR) for the trace test $\left(\lambda_{\text {trace }}\right)$ as suggested by Johansen (1988) Eq. 6:

$$
\lambda_{\text {trace }}(\mathrm{r})=-\mathrm{T} \sum_{\mathrm{i}=\mathrm{r}+1}^{\mathrm{p}} \ln \left(1-\hat{\lambda}_{\mathrm{i}}\right)
$$

Where:

$$
\begin{aligned}
\hat{\lambda}_{\mathrm{i}}= & \text { The largest estimated value of ith characteristic } \\
& \text { root (eigenvalue) obtained from the estimated } \Pi \\
& \text { matrix } \\
\mathrm{r}= & 0,1,2, \ldots \mathrm{p}-1 \\
\mathrm{~T}= & \text { The number of usable observations }
\end{aligned}
$$

The $\lambda_{\text {trace }}$ statistic tests the null hypothesis that the number of distinct characteristic roots is less than or equal to $r$, (where $r$ is 0,1 , or 2 ) against the general alternative. In this statistic $\lambda_{\text {trace }}$ will be small when the values of the characteristic roots are closer to zero (and its value will be large in relation to the values of the characteristic roots which are further from zero).

Alternatively, the maximum eigenvalue $\left(\lambda_{\max }\right)$ statistic as suggested by Johansen is Eq. 7:

$\lambda_{\max }(\mathrm{r}, \mathrm{r}+1)=-\mathrm{T} \ln \left(1-\hat{\lambda}_{\mathrm{r}+1}\right)$

The $\lambda_{\max }$ statistic tests the null hypothesis that the number of $\mathrm{r}$ co-integrated vectors is $\mathrm{r}$ against the alternative of $(\mathrm{r}+1)$ co-integrated vectors. Thus, the null hypothesis $r=0$ is tested against the alternative that $r=1, r=1$ against the alternative $r=2, r=2$ against the alternative $r=3$ and so forth. If the estimated value of the characteristic root is close to zero, then the $\lambda_{\max }$ will be small.

It is well known that Johansen's co-integration tests are very sensitive to the choice of lag length. Firstly, a VAR model is fitted to the time series data in order to find an appropriate lag structure. Schwarz (1978) is used to select the number of lags required in the co-integration test.

The Schwarz Criterion (SC) suggested that the value $p=1$ is the appropriate specification for the order of VAR model for United Kingdom. Table 2 shows the results from the Johansen co-integration test. 
Table 3: Vector error correction model Dependent

\begin{tabular}{llllll}
\hline variable constant & $\Delta \mathrm{BC}_{\mathrm{t}-\mathrm{I}}$ & $\Delta \mathrm{GDP}_{\mathrm{t}-\mathrm{I}}$ & $\Delta \mathrm{CPI}_{\mathrm{t}-\mathrm{i}}$ & ect $_{\mathrm{t}-1}$ \\
$\Delta \mathrm{BC}_{\mathrm{t}}$ & 0.05 & 0.39 & 0.006 & -1.05 & -0.01 \\
& {$[1.83]$} & {$[2.22]$} & {$[0.41]$} & {$[-1.25]$} & {$[-0.50]$} \\
& F-stat=1.44 & $\mathrm{DW}=2.50$ & $\mathrm{AIC}=-2.80$ & $\mathrm{SC}=-2.57$ & \\
\hline
\end{tabular}

Notes: [ ]: I denote the t-statistic values; $\Delta$ : Denotes the first differences of the variables; DW: Durbin-Watson statistic, AIC: Akaike Criterion, SC: Swchartz Criterion

Vector error correction model: Since the variables included in the VAR model are co-integrated, the next step is to specify and estimate a Vector Error Correction Model (VECM) including the error correction term to investigate dynamic behavior of the model. Once the equilibrium conditions are imposed, the VEC model describes how the examined model is adjusting in each time period towards its long-run equilibrium state.

Since the variables are co-integrated, then in the short run, deviations from this long-run equilibrium will feed back on the changes in the dependent variables in order to force their movements towards the long-run equilibrium state.

Hence, the co-integrated vectors from which the error correction terms are derived are each indicating an independent direction where a stable meaningful longrun equilibrium state exists.

The VEC specification forces the long-run behavior of the endogenous variables to converge to their cointegrated relationships, while accommodates short-run dynamics. The dynamic specification of the model allows the deletion of the insignificant variables, while the error correction term is retained. The size of the error correction term indicates the speed of adjustment of any disequilibrium towards a long-run equilibrium state (Engle and Granger, 1987). The error-correction model with the computed t-values of the regression coefficients in parentheses is reported in Table 3.

The final form of the Error-Correction Model (ECM) was selected according to the approach suggested by Hendry (Maddala, 1992). The general form of the Vector Error Correction Model (VECM) is the following one Eq. 8:

$$
\Delta \mathrm{Y}_{\mathrm{t}}=\beta_{1} \sum_{\mathrm{i}}^{\mathrm{n}} \Delta \mathrm{Y}_{\mathrm{t}-\mathrm{i}}+\beta_{2} \sum_{\mathrm{i}}^{\mathrm{n}} \Delta \mathrm{X}_{\mathrm{t}-\mathrm{i}}+\beta_{3} \sum_{\mathrm{i}}^{\mathrm{n}} \Delta \mathrm{Z}_{\mathrm{t}-\mathrm{i}}+\lambda \mathrm{EC}_{\mathrm{t}-\mathrm{i}}+\varepsilon_{\mathrm{t}}
$$

\section{Where:}

$\Delta \quad=$ The first difference operator

$\mathrm{EC}_{\mathrm{t}-1}=$ The error correction term lagged one period

$\Lambda=$ The short-run coefficient of the error correction term $(-1<\lambda<0)$

$\varepsilon_{\mathrm{t}} \quad=$ The white noise term
Granger causality tests: Granger causality is used for testing the long-run relationship between credit market development and economic growth. The Granger procedure is selected because it consists the more powerful and simpler way of testing causal relationship (Granger, 1986). and 10 :

The following bivariate model is estimated Eq. 9

$$
\begin{aligned}
& Y_{t}=a_{10}+\sum_{j=1}^{k} a_{1 j} Y_{t-j}+\sum_{j=1}^{k} b_{1 j} X_{t-j}+u_{t} \\
& X_{t}=a_{20}+\sum_{j=1}^{k} a_{2 j} X_{t-j}+\sum_{j=1}^{k} b_{2 j} Y_{t-j}+u_{t}
\end{aligned}
$$

In order to test the above hypotheses the usual Wald F-statistic test is utilized, which has the following form:

$$
\mathrm{F}=\frac{\left(\mathrm{RSS}_{\mathrm{R}}-\mathrm{RSS}_{\mathrm{U}}\right) / \mathrm{q}}{\mathrm{RSS}_{\mathrm{U}} /(\mathrm{T}-2 \mathrm{q}-1)}
$$

Where:

$\mathrm{RSS}_{\mathrm{U}}=$ The sum of squared residuals from the complete (unrestricted) equation

$\mathrm{RSS}_{\mathrm{R}}=$ The sum of squared residuals from the equation under the assumption that a set of variables is redundant, when the restrictions are imposed, (restricted equation)

$\mathrm{T}=$ The sample size

$\mathrm{q}=$ The lag length

The hypotheses in this test are the (Seddighi et al. 2000; Renfro, 2006) following Eq. 11 and 12:

$\mathrm{H}_{0}$ : $\mathrm{X}$ does not Granger cause $\mathrm{Y}$, i.e.,

$\left\{\alpha_{11}, \alpha_{12}, \ldots \ldots \alpha_{1 \mathrm{k}}\right\}=0$, if $\mathrm{F}_{\mathrm{c}}<$ critical value of $\mathrm{F}$

$\mathrm{H}_{\mathrm{a}}$ : $\mathrm{X}$ does Granger cause Y, i.e.,

$\left\{\alpha_{11}, \alpha_{12}, \ldots \ldots \alpha_{1 \mathrm{k}}\right\} \neq 0$, if $\mathrm{F}_{\mathrm{c}}>$ critical value of $\mathrm{F}$

And:

$\mathrm{H}_{0}$ : $\mathrm{Y}$ does not Granger cause $\mathrm{X}$, i.e.,

$\left\{\beta_{21}, \beta_{22}, \ldots \beta_{2 k}\right\}=0$, if $F_{c}<$ critical value of $F$

$\mathrm{H}_{\mathrm{a}}$ : Y does Granger cause $X$, i.e.,

$\left\{\beta_{21}, \beta_{22}, \ldots . \beta_{2 k}\right\} \neq 0$, if $F_{c}>$ critical value of $F$

The validity of the test depends on the order of the VAR model and on the stationarity or not of the variables. The results related to the existence of Granger causal relationships among credit market development, economic growth and inflation appear in Table 4. 


\section{RESULTS}

The observed t-statistics fail to reject the null hypothesis of the presence of a unit root for all variables in their levels confirming that they are nonstationary at $1 \%, 5 \%$ and $10 \%$ levels of significance However, the results of the PP, KPSS, LLC IPS and BR tests show that all variables are stationary of the same order when they are transformed into their second differences Table $1 \mathrm{a}$ and $1 \mathrm{~b}$.

Therefore, all series that are used for the estimation are non-stationary in their levels, but stationary and integrated of order one I(1), in their first differences. These variables can be co-integrated as well, if there are one or more linear combinations among the variables that are stationary.

The results that appear in Table 2 suggest that the number of statistically significant co-integrated vectors for United Kingdom is equal to 1 and is the following one:

$\mathrm{BC}_{\mathrm{t}}=-3.45 \mathrm{CPI}_{\mathrm{t}}+2.60 \mathrm{GDP}_{\mathrm{t}}$

The process of estimating the rank $r$ is related with the assessment of eigenvalues, which are the following for United Kingdom: $\bar{\lambda}_{1}=0.79, \bar{\lambda}_{2}=0.19$, $\bar{\lambda}_{3}=0.006$ Table 2 .

For United Kingdom, critical values for the trace statistic defined by Eq. 6 are 24.05 for none cointegrating vectors, 12.36 for at most one vector and 4.16 for at most two vectors at the 0.05 level of significance as reported by MacKinnon et al. (1999), while critical values for the maximum eigenvalue test statistic defined by Eq. 7 are 17.68 for none cointegrating vectors, 11.03 for at most one vector and 4.16 for at most two vectors respectively Table 2 .

Then the error-correction model with the computed t-values of the regression coefficients in parentheses is estimated. The dynamic specification of the model allows the deletion of the insignificant variables, while the error correction term is retained by the estimation of the co-integrated vector.

Table 4: Pairwise granger causality tests Sample: 1975-2007: Lags: 2

\begin{tabular}{llrl} 
Null hypothesis & Obs & F-statistic & Probability \\
\hline GDP does not granger cause BC & 33 & 3.8377 & 0.0337 \\
BC does not Granger cause GDP & & 0.4101 & 0.6674 \\
CPI does not granger cause BC & \multirow{2}{*}{33} & 3.7607 & 0.0358 \\
BC does not granger cause CPI & & 3.9703 & 0.0303 \\
CPI does not Granger cause GDP & \multirow{2}{*}{33} & 0.5370 & 0.5904 \\
GDP does not granger cause CPI & & 0.9840 & 0.3864
\end{tabular}

A short-run increase of economic growth per $1 \%$ induces an increase of bank credits per $0.006 \%$, while an increase of consumer price index per $1 \%$ induces a decrease of bank credits per 1.05 for United Kingdom Table 3.

The estimated coefficient of $\mathrm{EC}_{\mathrm{t}-1}$ is statistically significant and has a negative sign, which confirms that there is not any problem in the long-run equilibrium relationship between the independent and dependent variables in 5\% level of significance, but its relatively value (-0.016) for United Kingdom shows a satisfactory rate of convergence to the equilibrium state per period Table 3 .

The results of Granger causality tests indicated that there is unidirectional causal relationship between economic growth and credit market development with direction from economic growth to credit market development and a bilateral causality between inflation and credit market development for United Kingdom Table 4.

\section{DISCUSSION}

The model of banking system is mainly characterized by the effect of interest rates, investments and the circulation of money. However, bank development is determined by the size of bank lending directed to private sector at times of low inflation rates leading to higher economic growth rates.

Interest rate is not included in the estimated model of banking system due to the insignificance of estimation results. The significance of the empirical results is dependent on the variables under estimation.

Less empirical studies have concentrated on examining the relationship between economic growth and credit market development taking into account the effect of inflation rate. Most empirical studies examine the relationship between economic growth and stock market development.

The results of this study are agreed with the studies of Levine and Zervos (1998); Levine (2002) and Vazakidis and Adamopoulos (2009a; 2009b; 2010). However, more interest should be focused on the comparative analysis of empirical results for the rest of European Union members-states in future research.

\section{CONCLUSION}

This study employs with the relationship between credit market development and economic growth for United Kingdom, using annually data for the period 1975-2007. 
For univariate time series analysis involving stochastic trends, Phillips and Perron, (1988); Kwiatkowski et al. (1992) classical unit roots tests and Levin et al. (2002); Im et al. (1997); Breitung (2001) panel unit roots tests are calculated for individual series to provide evidence as to whether the variables are stationary and integrated of the same order.

The empirical analysis suggested that the variables that determine credit market development present a unit root. Therefore, all series are stationary and integrated of order one I (1), in their first differences. Since it has been determined that the variables under examination are stationary and integrated of order 1 , then the Johansen co-integration analysis is performed taking into account the maximum likelihood procedure.

The short run dynamics of the model is studied by analyzing how each variable in a co-integrated system responds or corrects itself to the residual or error from the co-integrating vector. This justifies the use of the term error correction mechanism.

The Error Correction (EC) term, picks up the speed of adjustment of each variable in response to a deviation from the steady state equilibrium. The dynamic specification of the model suggests deletion of the insignificant variables while the error correction term is retained. The VEC specification forces the longrun behavior of the endogenous variables to converge to their co-integrating relationships, while accommodates the short-run dynamics.

A short-run increase of economic growth per $1 \%$ leaded to an increase of bank credits per $0.006 \%$, while an increase of consumer price index per $1 \%$ leaded to a decrease of bank credits per $1.05 \%$ in United Kingdom.

Therefore, it can be inferred that economic growth has a positive effect on credit market development taking into account the negative effect of inflation rate on credit market development and economic growth.

The results of Granger causality tests indicated that there is unidirectional causal relationship between economic growth and credit market development with direction from economic growth to credit market development and a bilateral causality between inflation and credit market development for United Kingdom.

\section{REFERENCES}

Adamopoulos, A., 2010a. Financial development and economic growth: A comparative study between 15 European Union member-states. Int. Res. J. Finance Econ., 35: 143-149.

Adamopoulos, A., 2010b. The relationship between credit market development and economic growth. Am. J. Applied Sci., 7: 518-526.
Adamopoulos, A, 2010c. Stock market and economic growth: An empirical analysis for Germany, Bus. Econ. J., 1: 1-12.

Ball, L. and N.G. Mankiw, 1995. Relative-price changes as aggregate supply shocks. Q. J. Econ., 110: 161-193. DOI: 10.3844/ajassp.2010.518.526

Breitung, J., 2001. The local power of some unit root tests for panel data. 15: 161-177. DOI: 10.1016/S0731-9053(00)15006-6

Chang, T. and S.B. Caudill, 2005. Financial development and economic growth: The case of Taiwan. Ap. Econ., 37: 1329-1335. DOI: 10.1080/0003684042000338702

Chang, T., 2002. An econometric test of Wagner's law for six countries based on cointegration and errorcorrection modelling techniques. Applied Econ., 34: 1157-1169. DOI: 10.1080/00036840110074132

Choi, I., 1992. Effects of data aggregation on the power of tests for a unit root: A simulation study. Econ. Lett., 40: 397-401. DOI: 10.1016/01651765(92)90133-J

Christopoulos, D.K. and E.G. Tsionas, 2004. Financial development and economic growth: Evidence from panel unit root and cointegration tests. J. Dev. Econ., 73: 55-74. DOI: 10.1016/j.jdeveco.2003.03.002

Dickey, D. and W. Fuller, 1979. Distribution of the estimators for autoregressive time series with a unit root. J. Am. Stat. Assoc., 74: 427-431.

Engle, R.F. and C.W.J. Granger, 1987. Co-Integration and error correction: Representation, estimation and testing. Econometrica, 55: 251-276.

Granger, C.W.J., 1986. Developments in the study of cointegrated economic variables. Oxford Bull. Econ. Stat., 48: 213-228. DOI: 10.1111/j.14680084.1986.mp48003002.x

Im, K.S., M.H. Peasaran and Y. Shin, 1997. Testing for unit roots in heterogeneous panels. $\mathrm{J}$. Econometrics, 115: 53-74. DOI: 10.1016/S03044076(03)00092-7

IMF, 2006. International Financial Statistics Yearbook. 1st Edn., International Monetary Fund, ISBN: 1589065778, pp: 865.

Johansen, S. and K. Juselious, 1990. Maximum likelihood estimation and inference on cointegration-with applications to the demand for money. Oxford Bull. Econ. Stat., 52: 169-210. DOI: 10.1111/j.1468-0084.1990.mp52002003.x

Johansen, S. and K. Juselius, 1992. Testing structural hypotheses in a multivariate cointegration analysis of the PPP and the UIP for UK. J. Econ., 53: 211244. DOI: 10.1016/0304-4076(92)90086-7

Johansen, S., 1988. Statistical analysis of cointegration vectors. J. Econ. Dynam. Cont., 12: 231-254. DOI: 10.1016/0165-1889(88)90041-3 
Renfro, C.G., 2006. The practice of econometric theory: An examination of the characteristics of econometric computation. 1st Edn., Springer, Berlin, ISBN: 3540755705, pp: 311.

King, R.G. and R. Levine, 1993. Finance and growth: Schumpeter might be right. Q. J. Econ., 108: 717737. DOI: $10.2307 / 2118406$

Kiran B., N.C. Yavuz and B. Guris, 2009. Financial development and economic growth: A panel data analysis of emerging countries. Int. Res. J. Finance Econ., 30: 87-94

Kwiatkowski, D., P.C.B. Phillips, P. Schmidt and Y. Shin, 1992. Testing the null hypothesis of stationarity against the alternative of a unit root: How sure are we that economic time series have a unit root? J. Econometrics, 54: 159-178. DOI: 10.1016/0304-4076(92)90104-Y

Laopodis, N.T. and B.L. Sawhney, 2007. Dynamic interactions between private investment and the stock market: Evidence from cointegration and error correction models. Applied Financ. Econ., 17: 257-269. DOI: 10.1080/09603100600694327

Levin, A., C.F. Lin and C.S.J. Chu, 2002. Unit root tests in panel data: Asymptotic and finite-sample properties. J. Econometrics, 108: 1-24. DOI: 10.1016/S0304-4076(01)00098-7

Levine, R. and S. Zervos, 1998. Stock markets, banks and economic growth. Am. Econ. Rev., 88: 537558.

Levine, R., 2002. Bank-based or market-based financial systems: Which is better? J. Fin. Int., 11: 398-428.

MacKinnon, J.G., A.A. Haug and L. Michelis, 1999. Numerical distribution functions of likelihood ratio tests for cointegration. J. Applied Econ., 14: 563577.

Maddala, G., 1992. Introduction to Econometrics. 2nd Edn., Macmillan Pub. Co., New York, ISBN: 0023745452, pp: 631.

Newey, W.K. and K.D. West, 1987. A simple, positive semi-definite, heteroskedasticity and autocorrelation consistent covariance matrix. Econometrica, 55: 703-708.

Osterwald-Lenum, M., 1992. A Note with quantiles of the asymptotic distribution of the maximum likelihood cointegration rank test statistics. Oxford Bul. Econ. Statist., 54: 461-472. DOI: 10.1111/j.1468-0084.1992.tb00013.x
Phillips, P.C.B. and P. Perron, 1988. Testing for a unit root in time series regression. Biometrika, 75: 335346. DOI: 10.1093/biomet/75.2.335

Phillips, P.C.B., 1987. Time series regression with a unit root. Econometrica, 2: 277-301.

Schwarz, G., 1978. Estimating the dimension of a model. Ann. Stat., 6: 461-464.

Seddighi, H., K.A. Lawler and A.V. Katos, 2000. Econome-trics: A Practical Approach. 1st Edn., Routledge, London, ISBN: 0415156459, pp: 396.

Shan, J., 2005. Does financial development 'lead' economic growth? A vector auto-regression appraisal. Applied Econ., 37: 1353-1367. 10.1080/00036840500118762

Stiglitz, J.E. and A. Weiss, 1981. Credit rationing in markets with imperfect information. Am. Econ. Rev., 71: 383-410.

Vazakidis, A. and A. Adamopoulos, 2009a. Credit market development and economic growth, Am. J. Econ. Bus. Admin., 1: 34-40. DOI: 10.3844/ajebasp.2009.34.40

Vazakidis, A. and A. Adamopoulos, 2009b. Financial development and economic growth an empirical analysis for Greece. Am. J. Applied. Sci., 6: 14101417. DOI: 10.3844/ajassp.2009.1410.1417

Vazakidis, A. and A. Adamopoulos, 2009c. Stock market development and economic growth. Am. J. Ap. Sc., 6: 1932-1940. DOI: 10.3844/ajassp.2009.1932.1940

Vazakidis, A. and A. Adamopoulos, 2010. A causal relationship between financial market development and economic growth. Am. J. Applied Sc., 7: 575583. DOI:10.3844/ajassp.2010.575.583

Athanasios, V. and A. Antonios, 2010. The effect of stock and credit market development on economic growth an empirical analysis for Italy, Int. Res. J. Fin. Econ., 41: 33-42.

Vazakidis, A., 2006. Testing simple versus dimson market models: The case of the Athens stock exchange. Int. Res. J. Fin. Econ., 2: 26-34.

Katos, A.V., G. Pekos, E. Katsouli and C. Batzios, 1996. Saving-investment equilibrium in the European Union: An economic policy exercise. Riv. Int. Sci. Econ. Com., 43: 81-107. 